\title{
Effects of Varying Modes of Perfusion on Ovum Maturation and Ovulation in the Perfused Rabbit Ovary
}

\author{
Naoki AOYAMA*, Osamu TOYAMA, Yoshito YAMASAKI, \\ Yoshinori MIZOGUCHI, Kaori TAMITSU, Akihiko OHTA, and \\ Yasuhiko KANOH \\ Department of Animal Physiology, Meiji University, \\ 1-1-1 Higashimita, Tamaku, Kawasaki 214, Japan
}

\begin{abstract}
Using a perfused rabbit ovary, we studied the effect of luteinizing hormone (LH) secretion on the ovulation time and the maturity of ova with 2 modes of perfusion. One mode consisted of a constant level of human chorionic gonadotropin (hCG) in the medium (the constant mode of perfusion), and the other mode mimicked the profile of LH surge in the rabbit (the surge mode of perfusion). The mean numbers of ova ovulated in the 2 modes were almost equal. The mean ovulation time in the constant mode was shorter than that in the surge mode. In the constant mode, the percentage of ova in germinal vesicle stage was larger, and in metaphase II was smaller, than those in the surge mode, while the difference in metaphase I was insignificant. The results indicate that the maturities of the ova in the surge mode were more advanced than those in the constant mode. A reason for the occurrence of the difference might be the early occurrence of ovulation in the constant mode due to excessive action on the follicular wall by various proteolytic enzymes, which are activated by the higher concentration of hCG, when compared with that of the surge mode, in the latter half of the perfusion.
\end{abstract}

Key words: LH surge, Perfusion, Rabbit ovary, Ovum maturation.

(J. Reprod. Dev. 41: 153-158, 1995)

$\mathbf{T}$ he in vitro perfused rabbit ovary preparation has served as a useful tool for the study of ovulation. The system has allowed 1) a direct observation of ovulation, 2) the direct delivery of substances to the ovary that are thought to affect ovulation, and 3) the collection of aliquots of perfusion media for the determination of substances produced by the ovary during the periovulatory period, and the evaluation of ovum morphology at the time of ovulation under various experimental conditions $[4,6,7,9]$.

Accepted for publication: February 27, 1995

Correspondence: N. Aoyama

*Present address: Mitsubishi Yuka Bio-clinical Laboratories Inc., 3-30-1 Shimura, Itabashiku, Tokyo 174, Japan
Although the surge mode of luteinizing hormone (LH) secretion is a primary function causing ovulation, the physiological significance of the surge mode of secretion has not been discussed from the point of view of comparative studies between surge and constant modes of secretion using the perfusion system. In 1991, we succeeded in developing a system for perfusion of the rabbit ovary in vitro, in conformity with the system developed by Lambertsen et al. [7].

The present study was undertaken to clarify the physiological roles of the surge mode of LH secretion on mechanisms responsible for ovum maturation and ovulation. A comparison of the effects of two modes of perfusion was made. One mode was a perfusion with a medium containing 
a constant level of hCG (the constant mode of perfusion), and the other mode was that with a fluctuating level of human chorionic gonadotropin (hCG), mimicking the surge mode of LH secretion (the surge mode of perfusion).

\section{Materials and Methods}

\section{Animals}

Sexually mature New Zealand White virgin rabbits, purchased from Sankyo Laboservice (Tokyo), were used in the experiments. All the rabbits were isolated for a minimum of 3 weeks prior to the experimental procedure.

The rabbits were housed individually at $22 \mathrm{C}$, lighting controlled at $14 \mathrm{~L} 10 \mathrm{D}$, fed a restricted diet (Nihon Nosan, Yokohama) to prevent overweight because the retroperitoneal fat makes the surgical procedure more difficult, and given water ad libitum.

Each animal received sc injection of 150 IU of pregnant mare serum gonadotropin (PMSG) (Peamex Sankyo Zoki, Tokyo), regardless of their weight, $70 \mathrm{~h}$ prior to surgery. A laparotomy was performed using sc injection with $2 \mathrm{mg} / \mathrm{kg}$ of $\mathrm{xy}$ lazine hydrochloride (Celactar Bayer Japan, Tokyo) and $50 \mathrm{mg} / \mathrm{kg}$ of ketamine Hydrochloride (Ketalar Sankyo, Tokyo).

Major anastomosic connections to the ovary were ligated and the ovary was left intact to maintain ovarian circulation during cannulation procedure. The ovarian artery and vein were separated gently from the adipose and other tissues.

Procain hydrochloride (2\%) was applied locally to the artery to cause dilatation and to facilitate cannulation. A polyethylene cannula, $0.5 \mathrm{~mm}$ in outer diameter, was inserted and advanced until the tip was within approximately $5 \mathrm{~mm}$ of the artery. It was tied in place with a previously placed suture. The ovary was freed and placed on a dish. The ovary was gently flushed with cold tissue culture medium containing $4 \mathrm{U} / \mathrm{ml}$ of heparin sulfate to expel the remaining blood until it became pale. Then the ovary was suspended in the perfusion chamber.

\section{Perfusion apparatus}

The perfusion apparatus used in the constant mode of perfusion consisted of an open perfusion system with 4 major portions: a capillary

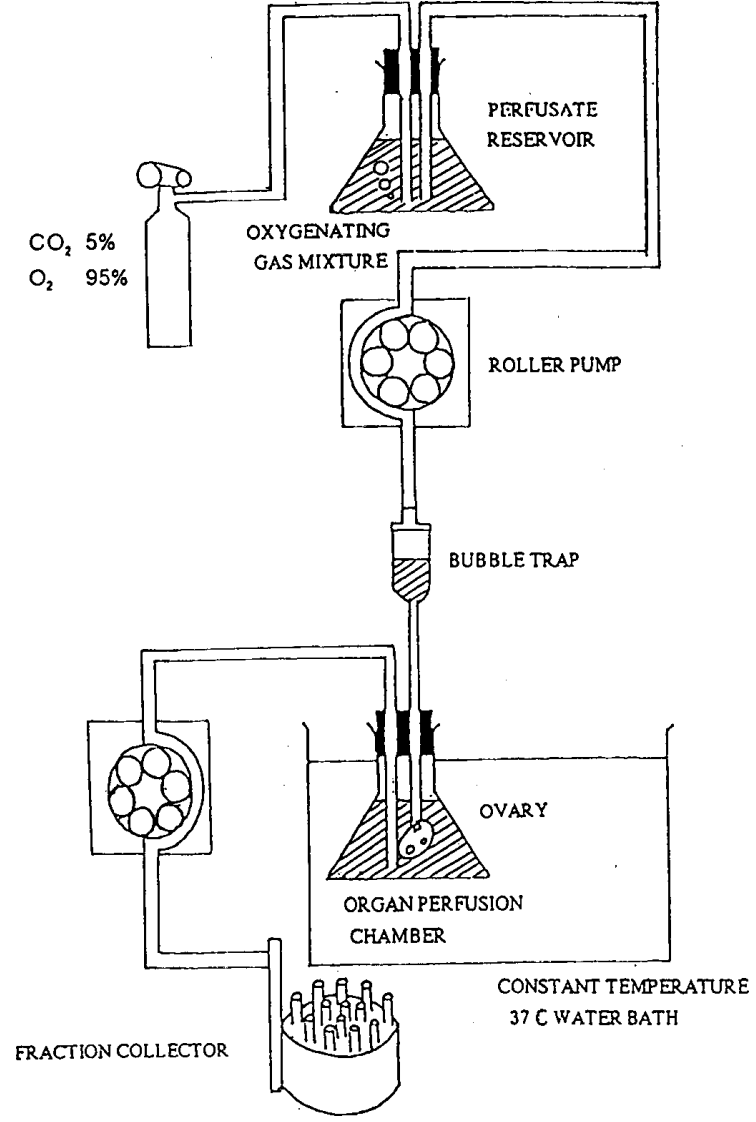

Fig. 1. Schematic representation of the perfusion apparatus for constant mode.

oxygenator, a roller pump, a perfusion chamber, and a fraction collector. Oxygenated perfusate was drawn from the oxygenator through a bubble trap and transported to the ovarian artery by the roller pump. All perfusions were carried out at a rate of $1.5 \mathrm{ml}$ of perfusate/ ovary/min. The perfusion cannula, fashioned from laboratory glass tubing fire-polished to a tapered tip, was fitted to the efferent tubing from the roller pump. This cannula was passed through a rubber stopper to provide support for the ovarian vasculature and seal the organ chamber during perfusion.

The culture medium emitted from the unligated ovarian vein was collected in test tubes on the fraction collector at $10 \mathrm{~min}$ intervals. The ovarian tissue was bathed in the efferent perfusate. The perfusion chamber was fashioned from a $50 \mathrm{ml}$ flask with an efferent perfusate channel. Both the organ chamber and coils of efferent tubing were immersed in a water bath maintained at $37 \mathrm{C}$ (Fig. 1). 


\section{Perfusion medium}

The perfusion medium consisted of M 199 tissue culture medium (Nissui Seiyaku, Tokyo) containing $20 \mathrm{IU} / 1$ of insulin, $200 \mathrm{IU} / 1$ of heparin, $50 \mathrm{mg} /$ 1 of streptomycin, $75 \mathrm{mg} / 1$ of penicillin $\mathrm{G}$ potassium, $666 \mathrm{IU} / 1$ of hCG (for the constant mode of perfusion only), $6 \mathrm{mg} / 1$ of $\mathrm{PGF}_{2 \alpha} 3 \%$ PVP-40 (polyvinyl-pyrrolidone Sigma, St. Louis, Mo.) and 5.95 $\mathrm{g} / 1$ of HEPES (2-hydroxyethylpiperazine-N-2 ethansulfonic acid, Wako Junyaku, Osaka) adjusted to a $\mathrm{pH}$ value of 7.4 with $\mathrm{NaHCO}_{3}$. Samples used for determinations of glucose and lactate were frozen and stored at $-20 \mathrm{C}$ until assayed.

\section{Surge mode of perfusion}

For the surge mode of perfusion, the following parts were added to the apparatus used in the constant mode of perfusion: four reservoirs for the

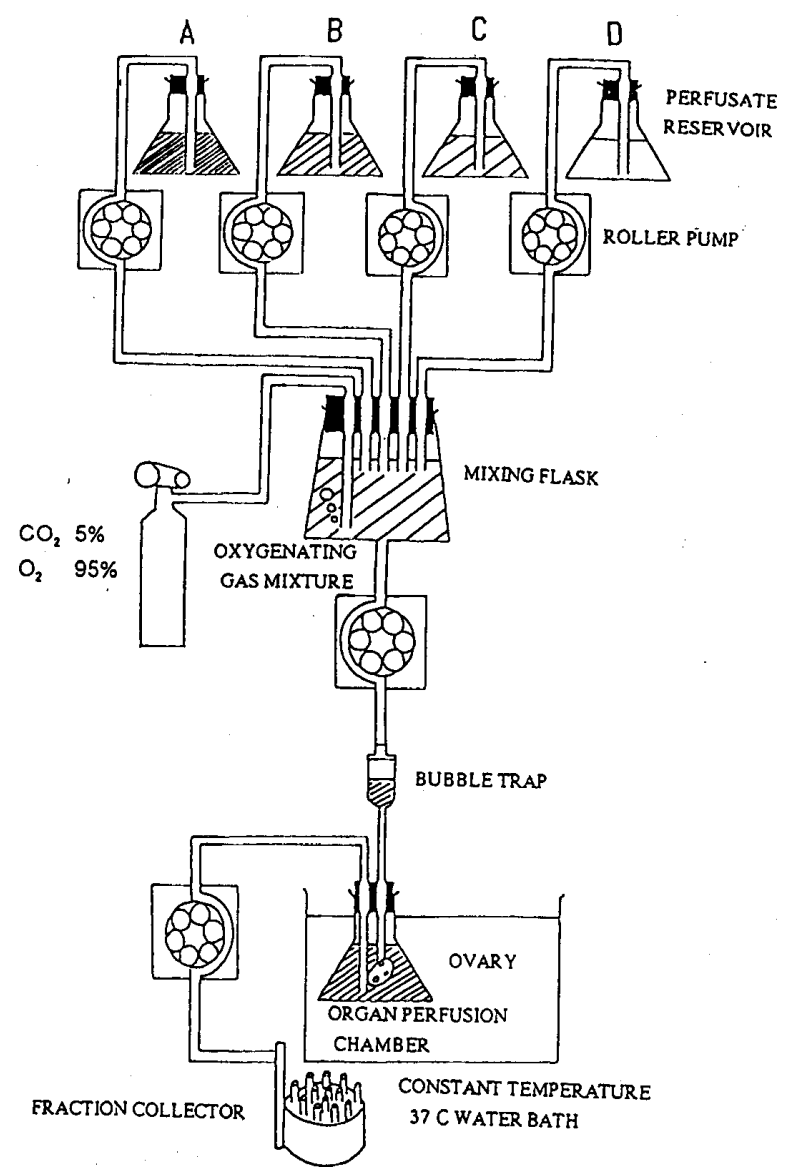

Fig. 2. Schematic representation of the perfusion apparatus for surge mode. mediums (the constitutents were same as those used in the constant mode of perfusion except the hCG concentration) which contained $2.73 \mathrm{IU} / \mathrm{ml}$, $1.09 \mathrm{IU} / \mathrm{ml}, 0.55 \mathrm{IU} / \mathrm{ml}$ and $0 \mathrm{IU} / \mathrm{ml}$ of hCG respectively, a mixing flask with magnetic stirrer, four roller pumps and the apparatus which was capable of regulating the pumps' rotation at the previously set-up speed of 10 min intervals (Mitsubishi programmable controller FX-16 MR, Mitsubishi Electric Co., Tokyo) (Fig. 2).

The media containing the various concentrations of hCG were introduced to the mixing flask, during the $10 \mathrm{~min}$ intervals, to constitute the perfusion fluids containing the desired hCG concentrations (Fig. 3) which mimicked the LH profile of rabbit LH surge reported by Kaynard et al. in 1990 [5]. We simulated this profile using hCG.

We used the same units of hCG, in total, in the surge mode as used in the constant mode, because the equivalence of IU of hCG to ng of LH was unknown.

\section{Observation and determination}

During the perfusion periods, observations were made at 15 min intervals and the time of occurrence of each ovulation was recorded.

Ovulated ova were examined microscopically to determine their stages of development. Ova were considered 1) meiotically inactive if the vesicular nucleus was a retained germinal vesicle (GV) stage,

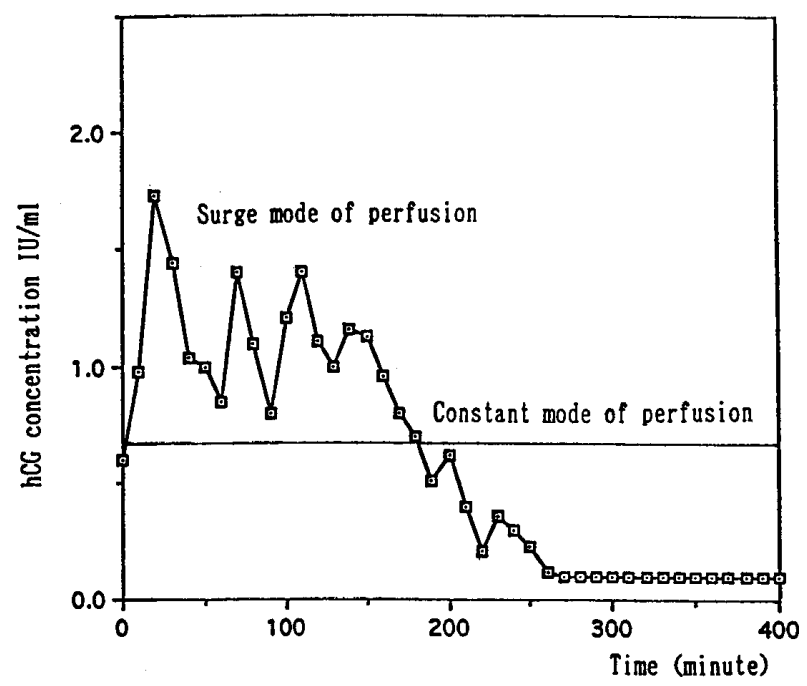

Fig. 3. hCG profile in the constant and surge mode of perfusion. 
2) at metaphase I (M I) if no nucleus or polar body was present and meiotic division has resumed, 3) at metaphase II if a polar body was extruded.

Glucose and lactate concentrations were measured using Glucose B-Test Wako (Wako Junyaku, Osaka) and Barker \& Summersons' method [1].

\section{Statistical Analysis}

Statistical analyses were made using Student's ttest.

\section{Results}

\section{Glucose and lactate determinations}

Concentrations of glucose and lactate in the perfused medium were determined as indices of cellular metabolic activity. The data for both parameters, plotted against time, indicate that glucose consumption and lactate production continued during both the perfusion periods (Fig. 4).

The concentration of glucose tended to decrease at the time of ovulation, although the reduction was insignificant in the constant mode. In the surge mode the glucose concentration of $832.5 \pm 21.0 \mu \mathrm{g} /$ $\mathrm{ml}$ at $12 \mathrm{~h}$ perfusion, nearly coinciding with the mean ovulation time of $11.8 \pm 0.2 \mathrm{~h}$ after the initiation of perfusion, was significantly $(\mathrm{p}<0.05)$ decreased compared with $948.4 \pm 22.5 \mu \mathrm{g} / \mathrm{ml}$ at 6 $\mathrm{h}$ perfusion.

The production of lactate in the surge mode was significantly $(\mathrm{p}<0.05)$ increased at 6 to $14 \mathrm{~h}$, compared with that at $2 \mathrm{~h}$ after initiation of perfusion, while in the constant mode no significant difference was observed.

\section{Number of ova ovulated}

The number of ova ovulated from ovaries perfused in the constant mode of perfusion was in agreement with Kobayashi et al. [6].

The difference between the 2 modes of perfusion was insignificant.

\section{Stage of maturity of ova ovulated}

The stage of the ova released with respect to the mode of perfusion was examined. The mean percentage of ova released at GV stage in the constant mode $(32.5 \pm 2.0)$ was significantly $(\mathrm{p}<0.05)$ higher than that in the surge mode of perfusion (13.8 \pm 5.0). At MI stage, there was no significant difference between the two modes of perfusion. At M II
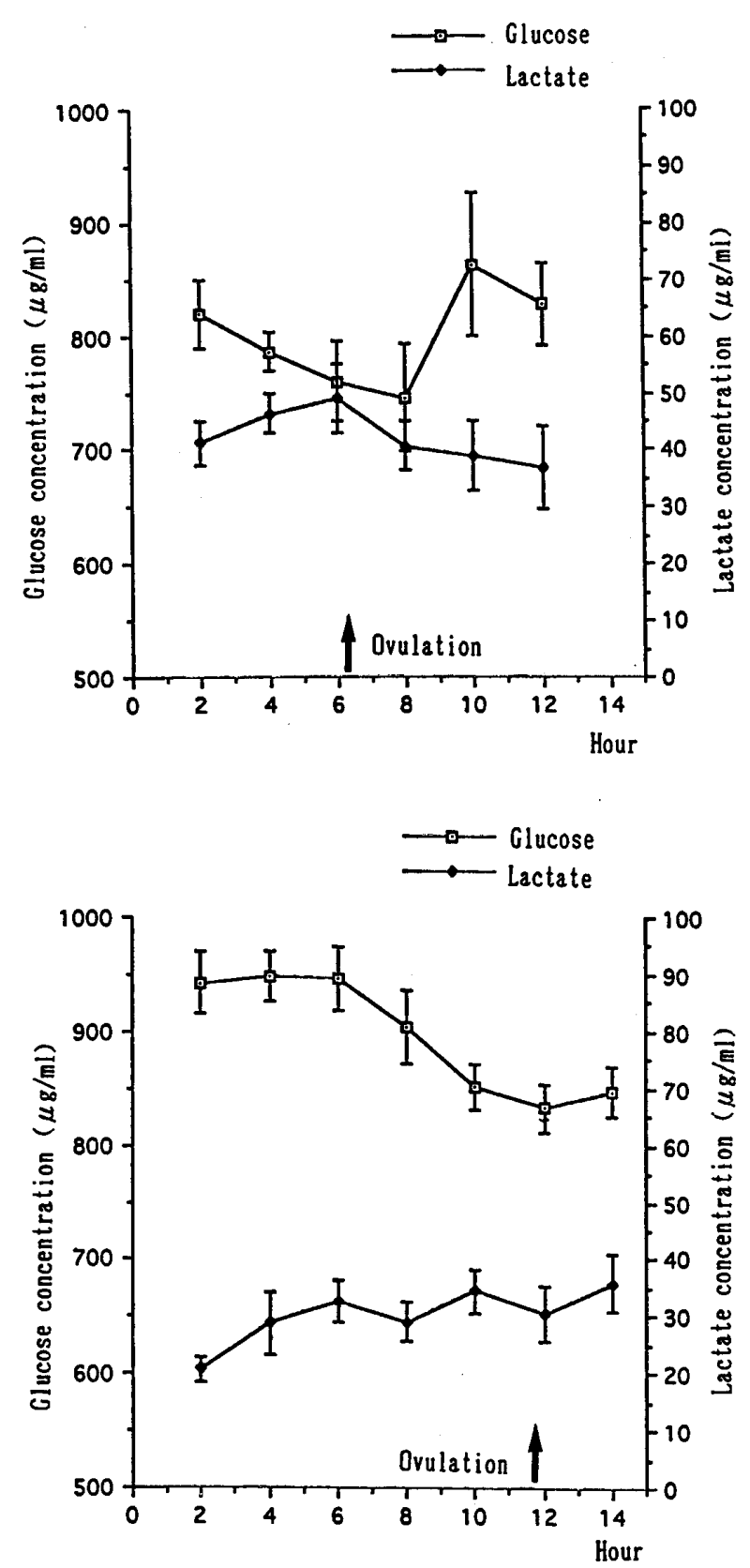

Fig. 4. Glucose and lactate concentrations during perfusions. Each point represents the mean \pm S.E. Upper panel: constant mode of perfusion $(n=5)$. Lower panel: surge mode of perfusion $(n=9)$. Arrows indicate the time of ovulation.

stage, the percentage in the constant mode $(3.0 \pm$ 1.9) was significantly $(p<0.05)$ lower than that in the surge mode of perfusion (18.3 \pm 4.4$)$ (Table 1$)$.

Time of occurrence of ovulation

The ovulation time of $6.3 \pm 0.2 \mathrm{~h}$ in the constant 
Table 1. Number and stage of ova ovulated after perfusion of hCG in rabbits

\begin{tabular}{|c|c|c|c|c|c|c|c|c|c|}
\hline \multirow{2}{*}{$\begin{array}{l}\text { Mode of } \\
\text { perfusion }\end{array}$} & \multirow{2}{*}{$\begin{array}{c}\text { No. of } \\
\text { ovaries }\end{array}$} & \multirow{2}{*}{$\begin{array}{c}\text { No. of } \\
\text { ova }\end{array}$} & \multirow{2}{*}{$\begin{array}{c}\text { No. of } \\
\text { ova/ovary }\end{array}$} & \multicolumn{2}{|r|}{ GV } & \multicolumn{2}{|r|}{ M I } & \multicolumn{2}{|r|}{ M II } \\
\hline & & & & No. & $\%$ & No. & $\%$ & No. & $\%$ \\
\hline Constant mode & 7 & 49 & $7.0 \pm 0.8$ & 16 & $32.5 \pm 2.0^{\mathrm{a}}$ & 31 & $64.5 \pm 2.6$ & 2 & $3.0 \pm 1.9^{a}$ \\
\hline Surge mode & 9 & 75 & $8.3 \pm 0.6$ & 10 & $13.8 \pm 5.0^{\mathrm{b}}$ & 51 & $67.9 \pm 6.7$ & 14 & $18.3 \pm 4.4^{\mathrm{b}}$ \\
\hline
\end{tabular}

Mean \pm S. E.

Percentages in the same column with different supercripts are significantly different $(p<0.05)$.

Table 2. Time of occurrence of ovulation after perfusion of hCG in rabbits

\begin{tabular}{lcc}
\hline Mode of perfusion & No. of ovaries & Hours after perfusion \\
\hline Constant mode & 7 & $6.3 \pm 0.2$ \\
surge mode & 9 & $11.8 \pm 0.2^{\star}$ \\
\hline
\end{tabular}

Mean \pm S. E. ${ }^{*} \mathrm{P}<0.05$, significantly different from the value of constant mode.

mode was significantly $(\mathrm{p}<0.05)$ earlier than that of the surge mode of perfusion (11.8 $\pm 0.2 \mathrm{~h}$ ) (Table 2 ). The mean ovulation time in the surge mode was almost equal in time to the duration between coitus and ovulation in vivo [8].

\section{Discussion}

In the present study we adopted a one side flow system, so that it was possible to mimick profiles of the surge mode of LH secretion in the rabbit.

The fact that glucose consumption and lactate production were observed during the perfusion period indicate that the metabolic activity of the ovary was maintained throughout the experiment. The increase in glucose consumption at ovulation indicates that the ovulation process is an energy consuming process.

Marked differences in the time interval from hCG stimulation to ovulation and the stages of maturity of the ova at ovulation were observed between the 2 modes of perfusion.

The causes of the larger percentage of GV stage ova observed at ovulation in the constant mode might be due to either an insufficient concentration of hCG in the medium or the shorter time interval from hCG stimulation to ovulation.

Brackett et al. [2] reported that after an injection of $75 \mathrm{IU}$ of hCG to PMSG treated rabbit, $72.7 \%$ of ova harvested in vivo were at the M II stage.

In the present experiment we used $100 \mathrm{IU}$ of hCG in $150 \mathrm{ml}$ of medium. So it was considered to be a sufficient concentration to grow over $72 \%$ of ova to M II stage, because in the perfusion system the hormone dose not detoxify as in vivo.

Therefore, the cause of the large percentage of GV stage ova at ovulation ovserved in the constant mode might not originate from an insufficient concentration of hCG.

Van Blerkom et al. [10] reported that the stage of maturity achieved by ova is a function of the time interval from gonadotropin stimulation to ovulation.

In the constant mode the hCG action on the proteolytic enzymes [3] was continuous during the 6 $h$ of perfusion causing excessive damage to the follicular wall resulting in early follicular rupture. In the surge mode, $11.8 \pm 0.2 \mathrm{~h}$ of time interval was longer than that of $6.3 \pm 0.2 \mathrm{~h}$ in the constant mode; and the larger number of oocytes of the ovaries perfused in the surge mode had more time to achieve the M II stage than those in the constant mode.

The cause of the more advanced stage of ova ovulated in the surge mode than that in the constant mode of perfusion might be due to the difference in the time interval of the ovum maturation between the 2 modes of perfusions.

In the surge mode, the high concentration of hCG during the first 90 min might have resumed the meiosis in sufficient numbers of oocytes; and the low concentration in latter period might protect the follicular wall from excessive proteolytic action of exzymes. A longer time for ovulation was therefore required and this provided a favorable 
condition for the ovum maturation.

It was considered that the ovulation was a sequential process of several distinct events and different quantities of hCG/LH, and a sufficient time interval, were required for the completion of the ovulation.

From the results described above, we may conclude that one of the physiological roles of the surge mode of LH secretion is to provide the different quantities of hormone required in the course of oocyte maturation, and to adjust the timing for the actions of proteolytic enzymes on the follicular rupture to ensure the completion of normal ovulation.

\section{Acknowledgement}

This study was supported by the Grant-in-Aid for Developmental Scientific Research from the Institute of Science and Technology, Meiji University.

\section{References}

1. Barker SB, Summerson WH. The colorimetric determination of lactic acid in biological material. J Biol Chem 1941; 138: 535-554.

2. Bracket BG, Mills JA, Jeitles GG. In vitro fertilization of rabbit ova recovered from ovarian follicles. Fertil Steril 1972; 23: 898-909.

3. Espey LL, Coons PJ. Factors which influence ovulatory degradation of rabbit ovarian follicles. Biol Reprod 1976; 14: 233-245.

4. Janson PO, LeMaire WJ, Kallfelt B, Holmes PV, Cajander S, Bjersing L, Wiqvist N, Ahren K. The study of ovulation in the isolated perfused rabbit ovary. I. Methodology and pattern of steroidogenesis. Biol Reprod 1982; 26: 456-465.

5. Kaynard AH, Pau KYF, Hess L, Spies HG. Gonadotropin-releasing hormone and norepinephrine release from the rabbit mediobasal and anterior hypothalamus during the mating-induced luteinizing hormone surge. Endocrinology 1990; 127: 11761185.
6. Kobayashi $\mathbf{Y}$, Wright $\mathbf{K H}$, Santulli R, Wallach EE. Ovulation and ovum maturation in the rabbit ovary perfused in vitro. Biol Reprod 1981; 24: 483490.

7. Lambertsen CJ, Greenbaum DF, Wright $\mathbf{K H}$, Wallach EE. In vitro studies of ovulation in the perfused rabbit ovary. Fertil Steril 1976; 27: 178188.

8. Lipner H. Mechanism of mammalian ovulation. In: Greep RO (ed.), Handbook of Physiology. section 7, Vol 2, Part 1. Washington DC: American Physiological Society. 1973; 409-437.

9. Stahler E, Spartling L, Bethge HD, Daume E, Buchholz R. Induction of ovulation in human ovaries perfused in vitro. Arch Gynak 1974; 217: 1-5.

10. Van Blerkom J, McGaughey RW. Molecular differentiation of the rabbit ovum. I. During oocyte maturation in vivo and in vitro. Dev Biol 1978; 63: 139-150. 